\title{
Effect of Roy's adaptation model based interventions on quality of life in patients with type II diabetes
}

\author{
Iram Majeed ${ }^{1}$, Sana Sehar ${ }^{1}$, Muhammad Afzal ${ }^{1}$, Syed Amir Gilani ${ }^{1}$, \\ Kousar Parveen ${ }^{1}$ and Rafique Ahmed ${ }^{2 *}$ \\ 1. Faculty of Allied Health Sciences, The University of Lahore-Pakistan \\ 2. Govt. Kot Khawaja Saeed Teaching Hospital, Lahore-Pakistan \\ *Corresponding author's email: khudijaqaiser786@gmail.com \\ Citation \\ Iram Majeed, Sana Sehar, Muhammad Afzal, Syed Amir Gilani, Kousar Parveen, and Rafique Ahmed. Effect of \\ Roy's adaptation model based interventions on quality of life in patients with type II diabetes. Pure and Applied \\ Biology. Vol. 9, Issue 1, pp332-339. http://dx.doi.org/10.19045/bspab.2020.90038
}

Received: 07/08/2019 Revised: 22/10/2019 Accepted: 01/11/2019

Online First: 06/11/2019

\section{Abstract}

Diabetes is a chronic illness and considered as one of significant health problem affecting quality of life. Roy' adaptation model based care plan is a non-invasive, non-medicated and cost efficient way to limit physical and psychological issues of patients with chronic diseases. Objective of present study was to see the effects of Roy's adaptation model based interventions on the quality of life in patients with type II diabetes. Quasi experimental approach with 40 type II diabetics was used. DiabetesSpecific Quality of Life Scale (D-39) was used to collect data before and after intervention. Intervention involving education regarding adaptive strategies was given for 12 weeks to type II diabetics. Close monitoring of patients was done for 12 weeks. Mean score of quality of life depicts an enhancement as difference in two means. Difference in means present a way to prove the positive effect of Roy model. So, these differences in various aspects of quality of life show that Roy's adaptation model has positive implications for type II diabetics. Results show Roy's adaptation model based interventions significantly affected QOL as p-value was 0.000 . Roy' adaptation model served a vital role in practice to enhance QOL of type II diabetics. Roy' adaptation model can be used effectively to manage chronic diseases where no cure is present and the only way is to maximize quality of life of patients. It could be concluded that there is a need to apply Roy' adaptation model in routine clinical practice to manage chronic disease. Clinical area with model based education could be a positive force towards better life.

Keywords: Adaptation; Diabetes; Model; Quality of Life

\section{Introduction}

American Diabetic Association defines diabetes as collection of metabolic diseases having characteristically high blood glucose levels due to some abnormality either in release of insulin or less body response to insulin [1]. World Health Organization defines diabetes, as a chronic illness that occurs when pancreas doesn't prepare enough insulin or when the body can't adequately utilize the insulin [2]. In 2014, approximately 422 million adults were identified as diabetic in contrast to 108 million in 1980. Diabetes was thought to be as a cause of at least 1.6 million deaths in 2016[3]. 
High mortality rate related to diabetes is attributable to maladaptive behaviors linked with modern life style changes, sedentary life style, lack of physical activity, unhealthy food and eating habits. Diabetes substantially effect QOL causing impairment in all functioning aspects of patient [4]. In Pakistan, $15 \%$ of diabetics suffer from foot complications and peripheral arterial disease [5].

For diabetics, physical activity has a major role. Problems arise in diabetics due to inactive life style habits. In fact, exercise helps to regulate blood glucose level along with prevention from diabetics' complications [6]. Anxiety has adverse effects on outcomes of diabetes as it prolongs the treatment modalities, decreases the quality of life and increase the risk of mortality. On the other hand, maladaptive coping behavior in diabetics lead to significant depression [7]. Diabetes has strong implications on psychology of individuals. Psychological factors are important determinants of patient's wellbeing. Self-concept strongly affects thinking and quality of life resulting in poor response to therapy, disease progression and even mortality [8].

Adaptive behaviors like lifestyle changes are utmost important in managing diabetes. A balanced diet and an increase level of physical activity can help to reduce the risk of complications and maladaptation in diabetics [9]. Diabetes has an effect on psychological functioning and quality of life of patients. Malfunctioning and poor quality of life is associated with further complications and co morbidities. These challenges emphasize the importance of adaptive capabilities in diabetics to control dysfunction [10]. Adaptive behaviors are the only way to manage diabetes, to prevent its complications and to improve quality of life [11].
Roy' adaptation model helps to adapt healthy behaviors in diseases which are impossible to cure. [12]. Roy 'adaptation model is important to promote individuals' adaptation in changing health care demands [13].

Diabetes has an effect on patients' quality of life [14]. Roy' adaptation model based care plan is a non-invasive non-medicated and cost efficient way to limit physical and psychological issues of patients with chronic diseases [15].

A study show that Roy adaptation model based care improved the maladaptive practices of patients [16]. Also, a study examined association between the various dimensions of RAM in patients with Parkinsonism. Roy's adaptation model aided to improve adaptation and quality of life [17]. Akyil, and Ergüney [18] conducted a study to see the impact of RAM. Findings revealed that Roy adaptation model has significant role on patients' adaptation in physiological, self-concept and role function mode.

A research depicts statistically significant differences in prenatal adaptation based on Roy adaption model. Women in intervention group showed better prenatal adaptation than those in control group [19].

Patel et al. [21] conducted a study to critically analyze the usefulness of RAM in various studies. Roy adaptation model was conceptualized as a best framework for patients' adaptation in chronic illnesses. Present study is aimed to see the effect of Roy's adaptation model based interventions on Quality of Life in patients with Type II diabetes

\section{Materials and methods}

A quasi experimental design was used. Target population was type II diabetic patients residing in the rural community of Pakistan. Purposive sampling technique was used in this study. Sample size was estimated as 40 individuals according to the sample size formula $\left(X_{1}=20.3, \quad X_{2}=18.13, \quad S_{1}=2.42\right.$,

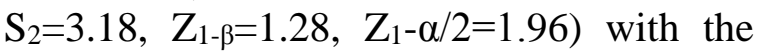


test power of $90 \%$ [22]. Inclusion criteria of the study involve patients (age 25-40 years) having definitive diagnosis of type II diabetes mellitus from more than 6 months whereas patients with chronic disability related to type II diabetes were excluded. Informed consent was signed by the participants before giving data. Confidentiality of the participants was assured.

First of all data regarding demographic and quality of life dimension was collected from participants through demographic and quality of life scale. Diabetic specific quality scale consists of 39 items [23]. This data served as baseline. Intervention based on Roy Adaptation model were applied to study group for 12 weeks and data was collected again by using same questionnaire on quality of life dimensions. Intervention involved adaptive strategies useful for diabetics like education related to diabetes, its complications, dietary approaches and coping strategies. Each session last for 60 minutes. After each education session close monitoring of blood pressure, blood sugar, BMI was done on weekly basis to assess any change. The data was analyzed using the SPSS software (version 24). Paired T test was used to analyze the pre and post data regarding quality of life.

\section{Results}

Demographics of study participants in table 1 depicts the demographic characteristics of study participants. Majority participants belong to age group of 30-35 years. Out of 40 participants, 28(60.9\%) were females. Most study participants were illiterate as frequency of illiterate participant is $18(45 \%)$, $13(32.5 \%)$ have elementary school education, $7(17.5 \%)$ have high school while only $2(5 \%)$ participants have college and higher education. 33(71.7\%) married and 07(15.2\%) unmarried individuals participated in this study. History of exercise was present in 19(47.5\%) participants. 14(35) have positive family history related to diabetes.

Table 1. Demographics of study subjects

\begin{tabular}{|c|c|c|}
\hline Variables & \multicolumn{2}{|c|}{ Type II Diabetics } \\
\hline Age & Frequency & Percentage \\
\cline { 2 - 3 } $31-30 Y \mathrm{Yr}$ & 08 & 20 \\
\cline { 2 - 3 } $36-40 Y \mathrm{Yr}$ & 17 & 42.5 \\
\cline { 2 - 3 } Gender & 15 & 37.5 \\
\cline { 2 - 3 } Male & 12 & 26.1 \\
\hline Female & 28 & 60.9 \\
\hline Education & & 45 \\
\hline Illiterate & 18 & 32.5 \\
\hline Primary & 13 & 17.5 \\
\hline High school & 07 & 5 \\
\hline College and higher & 02 & 71.7 \\
\hline Marital status & & 15.2 \\
Married & 33 & 47.5 \\
\hline Unmarried & 07 & 52.5 \\
\hline Regular Exercise & & \\
Present & 19 & 35 \\
\hline Absent & 21 & 65 \\
\hline Family history of diabetes & 14 & \\
\hline Present & 26 & \\
\hline Absent & & \\
\hline
\end{tabular}


Mean score of QOL in below mentioned tables 2, 3 and 4 depicts an enhancement as difference in two means. Difference in means present a way to prove the positive effect of Roy model. So, these differences in various aspects of QOL shows that Roy's adaptation model has positive implications for type II diabetics.

Mean scores give clear picture of mean differences. Mean 1 is means of mean scores of type II diabetics before interventions when
Roy; s model based interventions were applied, the mean score was enhanced.

Results of paired sample $t$ test indicates, $P$ value is significant i.e $p<.05$. Results are significant which show that Roy's adaptation model based interventions significantly affected QOL of type II diabetics. Means difference of 1.34 also shows positive results. Results show that Roy' model has positive effect on QOL in type II diabetics.

Table 2. Differences in means of QOL before and after intervention

\begin{tabular}{|c|c|c|c|c|c|}
\hline \multirow[b]{2}{*}{ Quality of Life } & \multicolumn{2}{|c|}{ Pre-Intervention } & \multicolumn{2}{|c|}{ Post-Intervention } & \multirow{2}{*}{$\begin{array}{c}\text { Enhancement } \\
\text { in means }\end{array}$} \\
\hline & Mean & S.D & Mean & S.D & \\
\hline 1. Your diabetes medication schedule & 2.06 & 1.35 & 4.38 & 1.44 & 2.32 \\
\hline 2. Worries about money matters & 2.6 & 1.15 & 3.8 & 1.56 & 1.20 \\
\hline 3.Decrease or lack of energy & 3.1 & 1.23 & 4.47 & 1.81 & 1.37 \\
\hline $\begin{array}{l}\text { 4. Following your doctor's prescribed } \\
\text { treatment plan for diabetes }\end{array}$ & 2.91 & 1.4 & 3.65 & 1.25 & 1.74 \\
\hline $\begin{array}{l}\text { 5. Food restrictions required to control } \\
\text { your diabetes }\end{array}$ & 2.47 & 1.38 & 4.4 & 1.43 & 1.93 \\
\hline 6. Concerns about your future & 3.47 & 5.01 & 5.32 & 1.82 & 1.85 \\
\hline 7.Other health problems beside diabetes & 2.75 & 1.42 & 3.50 & 1.45 & 0.75 \\
\hline 8. Stress or pressure in your life & 2.47 & 1.59 & 4.1 & 1.77 & 1.63 \\
\hline 9.Feeling of weakness & 2.55 & 1.27 & 2.75 & 1.68 & 0.25 \\
\hline 10. How far you can walk? & 2.69 & 1.10 & 4.23 & 1.50 & 1.54 \\
\hline 11.Need to perform exercises regularly & 2.41 & 1.20 & 3.21 & 1.78 & 0.90 \\
\hline 12.Loss of vision or blurred vision & 2.36 & 1.62 & 4.78 & 2.30 & 2.42 \\
\hline 13.Not being able to do what you want & 3.30 & 3.60 & 3.90 & 1.42 & 0.60 \\
\hline 14. Having diabetes & 2.36 & 1.20 & 4.98 & 1.55 & 2.62 \\
\hline $\begin{array}{l}\text { 15. Losing control of your blood sugar } \\
\text { levels }\end{array}$ & 2.39 & 1.36 & 3.13 & 1.54 & 0.74 \\
\hline 16. Other Illnesses Besides Diabetes & 2.33 & 1.30 & 4.13 & 1.52 & 1.80 \\
\hline 17. Testing your blood sugar levels & 2.19 & 1.07 & 3.90 & 1.39 & 1.71 \\
\hline $\begin{array}{l}\text { 18. The time required to control your } \\
\text { diabetes }\end{array}$ & 2.5 & 1.06 & 3.0 & 1.57 & 0.5 \\
\hline $\begin{array}{l}\text { 19. The restrictions your diabetes places } \\
\text { on your family and friends }\end{array}$ & 2.4 & 1.13 & 3.9 & 1.36 & 1.5 \\
\hline $\begin{array}{l}\text { 20. Being embarrassed because you have } \\
\text { diabetes }\end{array}$ & 2.17 & 1.16 & 3.89 & 1.36 & 1.72 \\
\hline 21. Diabetes interfering with your sex life & 2.25 & 1.23 & 3.76 & 1.34 & 1.51 \\
\hline 22. Feeling depressed or low & 2.17 & 1.65 & 3.34 & 1.78 & 1.17 \\
\hline 23. Problems with sexual functioning & 2.06 & 1.12 & 3.45 & 1.43 & 1.39 \\
\hline 24. Getting your diabetes well controlled & 2.64 & 1.22 & 3.15 & 1.76 & 0.51 \\
\hline 25. Complications From Your Diabetes & 3.03 & 1.25 & 3.98 & 1.87 & 0.95 \\
\hline $\begin{array}{l}\text { 26. Doing things that your family and } \\
\text { friends don't do }\end{array}$ & 2.97 & 1.32 & 4.45 & 1.47 & 1.48 \\
\hline
\end{tabular}




\begin{tabular}{|c|c|c|c|c|c|}
\hline $\begin{array}{c}\text { 27. Keeping a record of your blood sugar } \\
\text { levels }\end{array}$ & 2.56 & 1.23 & 3.76 & 2.34 & 1.20 \\
\hline 28. The need to eat at regular intervals & 2.83 & 1.44 & 3.10 & 1.90 & 0.27 \\
\hline $\begin{array}{c}\text { 29. Not being able to do housework or } \\
\text { other jobs around the house }\end{array}$ & 2.72 & 1.47 & 4.43 & 1.54 & 1.71 \\
\hline 30. A decreased interest in sex & 2.78 & 1.41 & 3.87 & 1.54 & 1.09 \\
\hline $\begin{array}{c}\text { 31. Having to organize your daily life } \\
\text { around diabetes }\end{array}$ & 2.67 & 1.20 & 4.65 & 1.34 & 1.98 \\
\hline 32. Needing to rest often & 2.67 & 1.60 & 4.23 & 1.32 & 1.56 \\
\hline $\begin{array}{c}\text { 33. Problems in climbing stairs or walking } \\
\text { up steps }\end{array}$ & 3.08 & 1.55 & 4.52 & 1.98 & 1.44 \\
\hline $\begin{array}{c}\text { 34. Having trouble caring for yourself } \\
\text { (dressing, bathing, or using the toilet) }\end{array}$ & 2.89 & 1.62 & 4.10 & 1.81 & 1.21 \\
\hline 35. Restless sleep & 2.40 & 1.42 & 3.01 & 1.90 & 0.59 \\
\hline 36. Walking more slowly than others & 2.25 & 1.32 & 4.09 & 1.46 & 1.84 \\
\hline 37. Being identifies as a diabetic & 2.47 & 1.48 & 3.56 & 1.67 & 1.09 \\
\hline 38. Having diabetes interfere with your \\
family life
\end{tabular}

Table 3. Paired samples statistics

\begin{tabular}{|c|c|c|c|c|c|}
\hline \multicolumn{2}{|c|}{} & Mean & $\mathrm{N}$ & Std. Deviation & Std. Error Mean \\
\hline \multirow{2}{*}{ Pair } & mean2 & 3.9238 & 40 & .58106 & .09304 \\
\cline { 2 - 6 } & mean1 & 2.5826 & 40 & .33331 & .05337 \\
\hline
\end{tabular}

Table 4. Paired samples test

\begin{tabular}{|c|c|c|c|c|c|c|c|c|c|}
\hline & \multicolumn{5}{|c|}{ Paired Differences } & \multirow{3}{*}{$\mathbf{t}$} & \multirow{3}{*}{ df } & \multirow{3}{*}{$\begin{array}{l}\text { Sig. }(2 \\
\text { tailed) }\end{array}$} \\
\hline & & \multirow[t]{2}{*}{ Mean } & \multirow[t]{2}{*}{$\begin{array}{l}\text { Std. } \\
\text { Deviat } \\
\text { ion }\end{array}$} & \multirow{2}{*}{$\begin{array}{l}\text { Std. } \\
\text { Error } \\
\text { Mean }\end{array}$} & \multicolumn{2}{|c|}{$\begin{array}{l}\text { 95\% Confidence } \\
\text { Interval of the } \\
\text { Difference }\end{array}$} & & & \\
\hline & & & & & Lower & Upper & & & \\
\hline $\begin{array}{c}\text { Pair } \\
1\end{array}$ & $\begin{array}{l}\text { mean2 } \\
\text { mean1 }\end{array}$ & 1.34128 & .58029 & .09292 & 1.15317 & 1.52939 & 14.435 & 39 & .000 \\
\hline
\end{tabular}

\section{Discussion}

The study was aimed to depict the effectiveness of Roy' adaptation model based intervention on QOL of type II diabetics. Findings of present study showed positive effect of Roy' model based interventions. As, means scores before and after interventions show an enhancement in mean QOL of type II diabetics. These results are consistent with the study having mean increase in scores based on Roy' model [25]. In comparison, a study with the mothers of mentally retarded children showed difference in mean scores before and after application of RAM based interventions.
RAM based interventions increased the means adaption scores in a group of mothers of mentally retarded children [24].

The study findings depict an increase in QOL in type II diabetics as mean scores were increased after intervention. Mean score of QOL of type II diabetics was 2.58 before intervention and 3.92 after intervention. So, QOL was increased in type II diabetics. A similar study conducted on patients with heart failure also depict an increase in QOL in patients on the basis of Roy' $\mathrm{s}$ adaptation model [26]. 
In this study, RAM model proved affective to enhance QOL in type II diabetics. Results of RAM model interventions as mean enhancement of 1.34 show that RAM has positive influence on QOL. These findings are similar with the study showing a signification increase in QOL of elderly after application of RAM [27]. In comparison, a study depicts no significant effect on mean scores based on Roy' model [14].

The present study show that Roy' model based interventions have positively affected QOL in type II diabetics as p-value is indicative of a signification effect. P-value is 0.000 reflecting a true positive effect of model on QOL in type II diabetics. Also, the study showed a positive effect of Roy model in patients with lower extremities amputation as p-value was less than 0.05. Their study showed significant effect of Roy model to enhance coping strategies in patients with lower extremities amputation [22]. Similar study was conducted with nursing home residents, to see impact of Roy model on their QOL. Findings were suggestive of a positive impact on QOL of nursing home residents [20].

\section{Conclusion, recommendation, weaknesses of study and strengths of study}

Roy' adaptation model served a vital role in practice to enhance QOL of type II diabetics. Ram can be used effectively to manage chronic diseases where no cure is present and the only way is to maximize QOL of patients. RAM could be proved a backbone in clinical practices with choric disease. So, it can be concluded that there is a need to apply RAM in routine clinical practice to manage chronic disease. Clinical area with model based education could be a positive force towards better life.

We would like to suggest the following recommendations:

- With the ever-increasing rate of urbanization around the world. It is essential to raise awareness about diabetes and its escalating complications around the world

- Lifestyle interventions including modified diet, increased physical activity, and weight loss are critical for all diabetes patients. For highly motivated patients, whose diabetes is at a relatively early stage, it is even possible to pursue lifestyle interventions for improved QoL.

- To develop training programs for diabetes management that focus on the preventive aspect and screening of complications rather than glycemic control and symptomatic treatment only.

This study was designed to be undertaken in one community. Therefore the transferability of the findings to other settings will be challenging. Secondly, purposive sampling technique was used in this study, which did not allow random selection of participant.

- In Pakistan up to the best of researcher knowledge, first time a study is conducted on Roy adaptation model. This study gives an insight on usefulness of Roy adaptation model for management of chronic diseases like diabetes. In literature, no such study is conducted that show the efficacy of adaptation model on different domains of quality of life.

- This research opens new doors for health care professionals to better manage the sufferings of their patients.

- This study would benefit the policy makers to incorporate such interventions in treatment regime for patients with diabetes.

\section{Authors' contributions}

Conceived and designed the experiments: I Majeed \& S Sehar, Performed the experiments: I Majeed \& M Afzal, Analyzed the data: I Majeed \& A Gilani, Contributed materials/ analysis/ tools: I Majeed \& K Perveen, Wrote the paper: I Majeed.

\section{References}

1. Association AD (2010). Diagnosis and classification of diabetes mellitus. Diabetes Care 33(Suppl 1): S62. 
2. Organization WH (2006). Definition and diagnosis of diabetes mellitus and intermediate hyperglycemia: report of a WHO/IDF consultation. World Hearth Org.

3. Organization WH (2016). World health statistics 2016: monitoring health for the SDGs sustainable development goals: World Health Organization.

4. Basit A, Riaz M \& Fawwad A (2015). Improving diabetes care in developing countries: The example of Pakistan. Diabetes Res and Clin Practice 107(2): 224-232.

5. Ali Z, Ahmed SM, Bhutto AR, Chaudhry A \& Munir S (2012). Peripheral artery disease in type II diabetes. $J$ Coll Physicians Surg Pak 22(11): 686-689.

6. Colberg SR, Sigal RJ, Fernhall B, Regensteiner JG, Blissmer BJ, Rubin RR \& Braun B (2010). Exercise and type 2 diabetes: the American College of Sports Medicine and the American Diabetes Association: joint position statement. Diabetes Care 33(12): e147-e167.

7. Bădescu S, Tătaru C, Kobylinska L, Georgescu E, Zahiu D, Zăgrean A \& Zăgrean L (2016). The association between diabetes mellitus and depression. $J$ of Med and Life 9(2): 120.

8. Harvey JN (2015). Psychosocial interventions for the diabetic patient. Diabetes, metabolic syndrome and obesity: targets and therapy 8: 29.

9. Sami W, Ansari T, Butt NS \& Ab Hamid MR (2017). Effect of diet on type 2 diabetes mellitus: A review. Inter $J$ of Health Sci 11(2): 65.

10. Cudjoe J, Fosu A \& Schlatter MC (2015). Health-Related Quality of Life Indicators in Ghana: Comparing Type 2 Diabetic and Control Groups.

11. Vissarion B, Malliarou M, Theofilou P \& Zyga S (2014). Improvement of diabetic patients nursing care by the development of educational programs. Health Psychol Res 2(1).

12. Clarke PN, Barone SH, Hanna D \& Senesac PM (2011). Roy's adaptation model. Nursing Sci Quarterly 24(4): 337344.

13. Naga BS \& Al-Atiyyat NM (2014). The Relationship between Pain Experience and Roy Adaption Model: Application of Theoretical Framework. Middle East J of Nursing 101(1149): 1-6.

14. Trikkalinou A, Papazafiropoulou AK \& Melidonis A (2017). Type 2 diabetes and quality of life. World J of Diabet, 8(4): 120.

15. Heshmati J \& Namazi N (2015). Effects of black seed (Nigella sativa) on metabolic parameters in diabetes mellitus: A systematic review. Complementary Therapies in Med 23(2): 275-282.

16. Maslakpak MH, Maghsoodi E \& Sheikhi $\mathrm{S}$ (2015). The Effects of a Care Program Based on the Roy Adaptation Model on Nursing Home Residents' Quality of Life. Modern Care J 12(4).

17. Babamohamadi H, Nobahar M, Saffari M, Samaei SA \& Mirmohammadkhani M (2016). Relationship among Dimensions of Roy Adaptation Model, General Health and Satisfaction with Life in Patients with Parkinson Disease. Health Sci 5(11): 467476.

18. Akyil RÇ \& Ergüney S (2013). Roy's adaptation model-guided education for adaptation to chronic obstructive pulmonary disease. J of Ad Nursing 69(5): 1063-1075.

19. Gonçalves M, Farcas D \& Dias S (2010). Concepts and strategies of action during pregnancy.

20. Aliakbarzadeh-Arani Z, Taghavi T, Sharifi N, Noghani F, Faghihzade S \& Khari-Arani M (2012). Impact of training on social adaptation in mothers of educable mentally-retarded children 
based on Roy adaptation theory. KAUMS $J$ (FEYZ) 16(2): 128-134.

21. Patel DV, Chandola H, Baghel MS \& Joshi JR (2012). Clinical efficacy of Shankhapushpi and a herbo-mineral compound in type-II diabetes. Ауи 33(2): 230.

22. Farsi Z \& Azarmi S (2016). Effect of Roy's Adaptation Model-Guided Education on Coping Strategies of the Veterans with Lower Extremities Amputation: A Double-Blind Randomized Controlled Clinical Trial. Inter J of Community Based Nursing and Midwifery 4(2): 127.

23. Boyer JG \& Earp JAL (1997). The development of an instrument for assessing the quality of life of people with diabetes: Diabetes-39. Medical Care 440453.

24. Borzou R, Khan MS, Falahinia GH, Mousavi S \& Khalili Z (2015). Effects of roy's adaptation model in nursing practice on the quality of life in patients with type II diabetes. $J$ of Nursing and Midwifery Sci 2(4): 1-7.

25. Mohammadpour A, Najafi S, Tavakkolizadeh J \& Mohammadzadeh F (2016). The Effects of the Roy's Adaptation Model on Primigravida Women's Self-Concept: A Randomized Controlled Trial. Asian J of Pharm Res and Health Care 8(1): 17-23.

26. Lakdizaji S, Hassankhani H \& Khalilzad $P$ (2015). Effect of training program based on Roy's adaptation model on quality of life of patients with heart failure: A randomized clinical trial. Nursing Practice Today 1(4): 183-191.

27. Maghsoodi E, Pak MHM \& Naseri O (2016). The Effect of Care Plan Application Based on Roy's Adaptation Model on The Spiritual Well-Being of Elderly People in Urmia Nursing Homes. Inter J of Med Res \& Health Sci 5(9): 158164. 